\section{Saúde e escola: reflexões em torno da medicalização da educação}

\author{
Health and school: thoughts on the medicalization \\ of education
}

\section{Salud y escuela: reflexiones en torno a la medicalización de la educación}

Sofia Castanheira Pais ${ }^{1,2}$

Isabel Menezes 2

João Arriscado Nunes 1

\title{
Resumo
}

É sabido que à escola chegam crianças e jovens com diferentes pontos de partida. O que não se sabe ao certo é até onde chegam essas crianças e jovens, e que percurso a escola lhes reserva, particularmente numa altura em que os profissionais de educação se veem divididos entre inúmeras tarefas (algumas meramente administrativas) e parece cada vez mais comum atribuir-se ao comportamento "pouco adequado" dos alunos explicações de natureza tendencialmente biomédica. Face à emergência crescente de transtornos e déficits torna-se, assim, inevitável refletir criticamente acerca do que efetivamente acarretam em termos de saúde pública. Este artigo centra-se numa investigação acerca do papel da escola no sucesso educativo e no desenvolvimento integral dos alunos sinalizados ou com indicação médica para ingestão de medicação a partir de diagnósticos "nebulosos". O conceito de medicalização adquire uma dimensão central e as suas implicações são discutidas baseando-se num conjunto de notas de campo e entrevistas realizadas com pais e profissionais de educação da Zona Norte de Portugal.

Medicalização; Instituições Acadêmicas; Criança; Adolescente

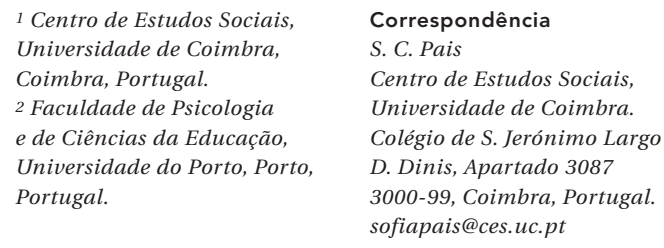

${ }^{1}$ Centro de Estudos Sociais, Universidade de Coimbra, Coimbra, Portugal.

2 Faculdade de Psicologia e de Ciências da Educação, Universidade do Porto, Porto Portugal. 


\section{Introdução}

Atualmente, verifica-se um aumento do número de diagnósticos médicos e de subsequente ingestão de medicação por crianças e jovens em idade escolar 1,2. Transtorno de déficit de atenção e hiperatividade, transtorno desafiador opositivo, transtorno obsessivo compulsivo e mesmo obesidade e dislexia constituem uma parte substancial das patologias ou distúrbios que ocupam as salas de aula das nossas escolas ${ }^{3}$. A emergência desses diagnósticos de significado expressivo no universo da saúde pública - que, em certos casos, podem considerar-se mais ou menos nebulosos pois, não raras vezes, revelam desinformação generalizada, quer do ponto de vista dos discursos, quer do ponto de vista das práticas a eles associada 4,5,6 - tende a estar, efetivamente, relacionada com a ideia de uma crescente medicalização da educação e da sociedade. A medicalização consiste, assim, em definir um problema em termos médicos, usar linguagem médica para descrevê-lo, adotar um enquadramento médico para compreendê-lo ou usar uma intervenção médica para "tratá-lo" 7,8. Esse "processo através do qual alguns aspetos da vida humana são considerados problemas médicos, quando anteriormente não eram entendidos enquanto patológicos" 2 (p. 123) parece estar atingindo proporções alarmantes em diversos países, tais como o Brasil, os Estados Unidos, o Reino Unido, Portugal etc., revelandose uma preocupação para pais, profissionais de saúde e de educação etc.

A esse respeito, verifica-se que a escola - tantas vezes com efeitos excludentes - acaba por reproduzir efeitos remediativos encarregando "a medicina de responder onde o ensino fracassou" 9 (p. 62). Do mesmo modo, o predomínio dos discursos médicos e a sua difusão pelos diversos canais da sociedade em formas simplistas, que tendem a naturalizar os problemas da criança/jovem, suscitam comentários e comportamentos potencialmente inadequados. $\mathrm{Ou}$ seja, é relativamente comum que profissionais de educação professem diagnósticos perante a observação de determinados comportamentos dos seus alunos. Indissociável da esfera social e política, tende a verificar-se que há muito que a medicina se socorre do conhecimento científico como recurso a partir do qual a profissão médica mobiliza a opinião pública e o Estado 10. Também por isso se verifica que essa tendência de avançar com possíveis diagnósticos ou "fabricar etiquetas" 11 (p. 53) sem perspectivar ou medir as implicações que daí advêm não estão confinadas à escola nem aos seus profissionais. Pelo contrário, estende-se aos mais diversos contextos e atores, negligenciando-se aspectos de na- tureza ética o que, em larga escala, resulta no fortalecimento das fragilidades já apresentadas pelas crianças, jovens e suas famílias 6 .

Inevitavelmente, o rótulo permite não apenas designar a pessoa, como facilitar a aceitação social do próprio, dado que as expectativas sociais a seu respeito estabilizam. O rótulo ou diagnóstico validado por aqueles que detêm o conhecimento e o poder médico provocam, em nível psicossocial, uma série de consequências e respostas sociais relativas à posição, aos papéis sociais, à autoimagem e autoestima da própria pessoa ${ }^{12}$. No entanto, é esse processo de medicalização que impera nos circuitos educativos e sociais e com o qual é difícil romper 13. Dessa forma, essa tendente biopsicologização de comportamentos de natureza socioeducativa resulta, não raras vezes, num exercício de classificação e discriminação invariavelmente em função da capacidade de resposta de instituições e agentes situados num determinado contexto ${ }^{14}$. Isso é, não encontrando estratégias adequadas e atores capazes de trabalhar diferenciadamente, o recurso a alternativas químicas torna-se potencialmente mais ponderável 15,16 . Similarmente, alguns autores têm revelado que os efeitos psicoativos dessas alternativas químicas têm sido vistos como potenciais contributos para a melhoria da qualidade das experiências no interior da sala de aula, dado que tendem a reduzir o sentido de agência das crianças e dos jovens medicados 17,18. Assim, este artigo pretende questionar o espaço que é dado à criança e ao jovem diagnosticado para se implicar na alteração de estratégias pedagógicas que visam à sua integração e bem-estar no espaço escolar.

\section{Metodologia}

Tratar cientificamente os fatos sociais é, por vezes, uma tarefa árdua e que requer uma atitude desafiadora 5. Veja que, "se há uma ciência das sociedades, é preciso confiar que ela não consista numa mera paráfrase dos preconceitos tradicionais, mas que nos faça ver as coisas de um modo diferente do habitual, porque toda a ciência tem por objetivo realizar descobertas e todas elas perturbam mais ou menos as opiniões formadas" 5 (p. 7). Foi, pois, na esteira dessa ideia que se avançou com o estudo que resulta no presente artigo.

Assim, é seu objetivo recolher percepções e experiências de profissionais de educação e pais sobre a emergência de diagnósticos nebulosos e os efeitos da medicação, quer na qualidade das experiências sociais, quer na performance acadêmica das crianças e jovens com diagnósticos "nebulosos". Para tal, envolveram-se três 
profissionais de educação, duas mães de crianças e jovens em idade escolar e uma representante de uma associação de pais, no processo de investigação que decorreu entre março de 2014 e janeiro de 2015, na Zona Norte de Portugal. A escolha desses sujeitos de pesquisa levou em consideração a diversidade de experiências vividas e papéis desempenhados por cada um. No caso das profissionais de educação, o critério prendeu-se com a diferenciação no que concerne ao desempenho de funções no espaço escolar (designadamente na figura do professor e do coordenador de educação especial) e com a experiência de ensino em anos/graus escolares distintos (1o ciclo do ensino básico e ensino secundário, respectivamente). No que diz respeito às mães que participaram do estudo, o critério de seleção baseou-se no fato de todas terem filhos/ as adolescentes. Remeteu também para a existência e não existência de diagnóstico de doença, e finalmente levou em consideração a experiência (bem e mal sucedida) em termos de efeito do uso da medicação e subsequente decisão no que concerne à interrupção ou manutenção da mesma. Foram realizadas entrevistas semiestruturadas, recorrendo-se igualmente a notas de campo e à observação participante. O envolvimento de todos os implicados foi voluntário, garantindolhes total confidencialidade e anonimato.

$\mathrm{O}$ estudo que aqui se apresenta assume um pendor essencialmente qualitativo, privilegiando o registro de proximidade construído com os participantes, assim como a preservação dos seus discursos. Em termos de métodos de coleta de dados, a entrevista permitiu aceder às experiências de vida dos participantes do estudo, nomeadamente no nível das suas principais fragilidades e potencialidades, ou não fosse uma das formas mais comuns e poderosas de compreender os outros seres humanos 14 . Após a realização das entrevistas, procedeu-se à transcrição das mesmas, seguindo-se a sua devolução aos participantes para que lessem e procedessem a eventuais alterações no texto resultante dos seus discursos. Posteriormente, trataram-se os dados por meio de análise de conteúdo.

No que toca à observação, optou-se por um formato em que o investigador, in locu e em presença dos envolvidos no estudo de forma autorizada, pudesse participar da ação que decorria. Desenvolveu-se, por conseguinte, observação participante, tendo sido possível, a par das notas de campo, fazer o registo de inúmeros dados descritivos da linguagem e dos comportamentos dos participantes ${ }^{15}$. O fato de se privilegiarem os contextos naturais das pessoas envolvidas neste estudo, designadamente as duas crianças/jovens anteriormente mencionadas por referência às suas mães, permitiu, em larga medida, captar as suas (re)ações espontâneas, assim como desenvolver uma ideia sobre a maneira como interpretam diversos aspectos do mundo e, em particular, do seu universo mais nuclear, tal como o bairro, a escola ou o centro de estudo. A organização das notas de campo seguiu uma orientação essencialmente cronológica, tendo em conta que foi possível estar várias vezes com alguns intervenientes deste estudo. Quer as entrevistas, quer o processo de observação, decorreram em espaços escolhidos pelos participantes e com a sua devida autorização. As notas de campo foram realizadas após a interação com os envolvidos e fora dos seus ambientes naturais. Reconhece-se que o uso desses três métodos contribuiu para pôr em perspectiva diferentes formas de experienciar o fenômeno da medicalização e, particularmente, aceder de modo mais profundo às suas implicações.

Perfazem um total de seis as participantes deste estudo. As profissionais de educação envolvidas nesta investigação são três e têm em comum o fato de trabalharem em escolas públicas da Zona Norte do país. Duas delas são professoras, sendo que uma leciona no 1o ciclo do ensino básico e a outra no ensino secundário, a terceira é coordenadora de educação especial. Neste artigo, referimo-nos a essas profissionais adotando os seguintes nomes: Carla (professora do 1o ciclo), Dora (professora do ensino secundário) e Vitória (coordenadora de educação especial). Por sua vez, as mães envolvidas neste estudo têm filhos em idade escolar, com 12 e 15 anos, e partilham o fato de terem ambos indicação médica para o uso de medicação para transtorno de déficit de atenção e hiperatividade. A fim de manter o anonimato, os nomes fictícios das mães e das crianças/jovens neste trabalho serão: Maria (mãe da Joana de 12 anos) e Ana (mãe do André de 15). Finalmente, a representante da associação de pais entrevistada tem um filho com 13 anos sem diagnóstico de qualquer tipo de patologia ou transtorno. A essa mãe atribuiremos o nome de Sara.

\section{Resultados}

\section{A escola: perscrutando discursos e sentidos}

A relação entre a escola e as famílias que fazem parte deste trabalho permite elencar três dimensões essenciais para problematizar as implicações de processos de medicalização da educação. A primeira dimensão recai sobre os resultados, isto é, reforça-se o peso atribuído às notas e, portanto, ao fato de as crianças e os jovens darem 
ou não prova de sucesso acadêmico. Veja que a experiência de Joana relatada pela mãe (Maria), quando aborda a questão do diagnóstico e da orientação medicamentosa, passa por um percurso sinuoso, embora atualmente mais bem-sucedido: "O outro ano e o ano passado reprovou, [agora] as notas estão boas. Vou falar com a professora muitas das vezes. E digo-lhe que qualquer coisa me ligue" (Maria).

As palavras de Maria permitem captar outro aspecto relevante: a articulação entre a performance acadêmica e o profissional de educação. "Agora as coisas estão diferentes e esta professora também é outra (...)". E disse-lhe logo: "Se realmente achar que a Joana fez asneira, por favor, mande-me na caderneta, que nós vamos falando por caderneta; quando tem alguma coisa especial, telefone-me, por favor, que eu dirijo-me aqui", "Pode estar sossegada, Dona Maria, que eu faço isso" e "Hoje ela tem umas notas boas". Independentemente de Maria, mãe de Joana, se disponibilizar para ir à escola mediante solicitação da professora, o fato de fazer referência - quase imediata - à eventualidade de a filha fazer alguma bobagem não deixa de reforçar a ideia de que a escola tende a convocar os pais e/ou responsáveis quando acontecem incidentes desagradáveis relacionados com os seus filhos/educandos, e não para reforçar episódios e conquistas positivas na sua vida escolar. Corroborando essa tendência, as notas de campo permitem recordar que, à porta da escola onde foi feita realizada uma das entrevistas deste estudo, se ouvia um pai comentando com desagrado: "estou cansado de pedir ao patrão para vir à escola do meu filho a meio do dia para ouvir que é mal-educado e não quer estudar!".

Um terceiro aspecto, interligado com os já mencionados, remete para a motivação das crianças e dos jovens para o espaço e as atividades de sala de aula. A esse respeito, Ana recorda o desinteresse do filho André quando se referia à escola: "para ele corria sempre tudo bem, entrava em casa e perguntava-lhe: está tudo bem?", e o André dizia sempre: "tá tudo bem, não há nada de diferente". Também Maria, em tom de lamento, admite: "Eu queria muito que a Joana fosse à biblioteca e fosse buscar um livro e que lesse, que não o rasgasse. A Joana não gosta muito de matemática, mas não é ela a única que não gosta de matemática (...)". Revendo algumas notas de campo registradas com base nas interações de Joana, cristaliza-se o episódio em que:

“(...) naquele recreio grande, viam-se crianças correndo atrás de uma bola, outras brincando com carros e bonecas, e Joana, com uma amiguinha, lá estava ensaiando os passos de dança da Violeta [uma referência à música e ao entreteni- mento televisivo para as crianças portuguesas]. No meio das risadas e dos gestos repetidos que as duas meninas faziam, ocupavam momentos de paragem para recuperar o folgo e rabiscar numa parede [qual caderno improvisado!] do centro de estudo os nomes das amigas que iriam participar no grande espetáculo da Violeta. Ouvia-se Joana reclamando: já disse que sou eu que escrevo!".

Esse excerto permite, de algum modo, depreender que a resistência de Joana pode não ser necessariamente às letras e aos livros, mas ao enredo escolarizado que envolve. Para além disso, Sara - representante da associação de pais acrescenta também que "um fator que as pessoas não conseguem compreender é que quando os alunos se desinteressam das atividades escolares há muitas coisas que estão por trás e que importa considerar". Será que a escola, os seus profissionais e os demais contextos e agentes que circundam a vida das crianças e dos jovens procuram, de fato, perceber o que motiva esse desinteresse?

\section{A emergência de diagnósticos}

Relativamente à referenciação das crianças e, posteriormente, ao surgimento do diagnóstico, percebe-se pelos discursos das pessoas entrevistadas e pelas notas de campo que é sobretudo a partir da escola que emergem as primeiras impressões sobre a necessidade de um olhar mais atento para um potencial problema. A escola é, pois, um contexto privilegiado de "mediação de mecanismos de diagnóstico" 16 (p. 445). Observem: "nós começamos a perceber que o André não conseguia acompanhar na escola, e os professores diziam que ele não estava quieto. Começamos a perceber que ele não trazia nada da sala de aula" (Ana). Nesse sentido, o alerta tende a ser transmitido pelos pais aos profissionais de saúde, tendo por base a referência da escola e dos profissionais de educação que, como argumenta Graham 17, tendem a ser uma figura central na discriminação de diferentes categorias de alunos. Assim, se depreende também do discurso de Maria: “ $a$ médica perguntou por que estávamos lá e eu disse-lhe que era porque a Joana aprendia mal (...). E porque eu disse que a Joana é irrequieta".

Paralelamente ao eventual comprometimento do processo de aprendizagem e das manifestações de falta de quietude na sala de aula, a dimensão emocional é também identificada, quer por Ana: "o André teve uma história difícil e também tinha problemas emocionais, isso claro, influencia", quer por Sara: "isto passa muito pela parte emocional. Quando as crianças são mesmo muito frágeis, isso está a comprometer todas as outras áreas, a socialização por exemplo". Maria corrobora admitindo que, no caso de Joana: “as 
coisas que já viveu possam contribuir, mas a minha filha não é mais nem menos que ninguém na escola e deve ter as mesmas oportunidades que os outros para aprender". Nessa linha, acrescenta também que o fato de a filha ter tido cinco professores em dois anos letivos em nada favoreceu à sua aprendizagem, questionando: "se tinha dificuldade na escola, como é que podia aprender melhor com tantos professores a entrar e a sair?".

No que tange ao processo que decorre desde a referenciação da escola até o diagnóstico do profissional de saúde, Sara considera que tende a existir uma elevada pressão sobre todos os intervenientes com responsabilidade ao longo deste processo: "a escola também não consegue, os pais não têm consciência, e muitas vezes levam ao médico porque a professora diz que não sei quê... Se calha de o médico não ser consciente ou não conseguir acertar no diagnóstico, o mais fácil é calar a mãe (...). E com isso sossegar a professora. E, assim, o filho vai estando mais ou menos sossegado (...). Estamos adiando e acumulando problemas". Apesar dessa carga sobre o processo que antecede o diagnóstico e a possível prescrição de medicação, Ana salienta que é necessário ser cauteloso: "no nosso caso, andamos muito tempo até confirmar o diagnóstico, e consultamos vários profissionais de saúde".

A esse respeito, destaca-se ainda o fato de, por um lado, para muitos dos participantes deste trabalho, esses diagnósticos estarem surgindo com mais frequência: "há cada vez mais alunos com diagnósticos deste gênero e que tomam medicação, sobretudo até aos 16 anos. No secundário não encontro tantos" (Dora). Por outro lado, subentende-se que na opinião de alguns intervenientes, nomeadamente Carla, esses diagnósticos estão associados a situações de risco e a escolas ou agrupamentos caracterizados pela própria por serem "mais complicados". A associação a processos de diagnóstico "nebulosos" e subsequente uso de medicação apenas a contextos de risco é, no entanto, rebatida por inúmeros estudos 18,19,20 que revelam que este argumento permite apenas veicular preconceitos que estereotipam grupos de maior vulnerabilidade e sem voz para reivindicarem direitos para além dos que adquirem contornos de natureza biológica. Ou seja, há evidências na literatura que, contrariamente ao que Carla referiu, permitem interpretar e desconstruir o conceito de medicalização com base em poderes que se instituem e perpetuam, veiculando interesses políticos (e a outros que tornam a indústria farmacêutica indissociável desta discussão) e, portanto, por relação a fatores contextuais, geográficos, sociais, culturais e econômicos 21,22,23.
As implicações educativas e sociais da medicação

No que diz respeito ao uso efetivo de medicação para essas epidemias do século XXI (estes distúrbios diagnosticados), neste caso transtorno de déficit de atenção e hiperatividade, as experiências partilhadas pelas mães são distintas, embora os resultados pareçam semelhantes. No caso de Maria, os efeitos da medicação e a descrença no diagnóstico feito pelo profissional de saúde motivaram-na a cessar a medicação da filha: " $E u$ achava a Joana muito mole com os comprimidos que a médica me receitou (...). A meio do caminho vinha de tal maneira que mal se segurava. $E$ agora a médica mandou tomar um comprimido só. Mas não toma". No caso de Ana, a medicação foi mantida de acordo com a prescrição do médico, destacando-se os seus efeitos no nível do sucesso acadêmico: "Foi no último período do $6 \underline{0}$ ano que ele começou a tomar e foi um sucesso. Ele conseguiu uma maior concentração, melhorou bastante as notas".

Apesar do reconhecimento dos efeitos a esse nível, Ana identifica implicações negativas para o filho, confessando que: "ele não quer tomar, ele prefere tirar os $20 \%$ [admitindo que a escala de avaliação é entre 0 e 100\%] do que tomar, porque tem a noção de que perde energia (...). Outro dia, ele até dizia que parecia um velhinho, que só tomava comprimidos. Claro que me custa ver o meu filho assim, particularmente pelas incertezas que esta medicação me suscita em termos de futuro, mas acredito que é o melhor para ele". A esse respeito, as notas de campo registradas depois das interações com a professora Dora permitem olhar para esse cenário inerente ao uso de medicação por outro prisma: "Tenho um aluno que me dá pena. Está nas aulas dopado, com os olhos vidrados. Estava habituada a vê-lo participativo, ele costumava ser bastante interventivo e tinha uma capacidade de concentração enorme, $e$ isso via-se em desenho, mas agora não o reconheço".

A propósito da ingestão de medicação para distúrbios dessa natureza, Vitória supõe que “todas as turmas, num universo que vai desde os 22 aos 26, têm alunos medicados, com pais com um nível, às vezes, mesmo até de escolaridade bastante elevado a acreditarem que há medicamentos que realmente ajudam a tirar melhores notas". Corroborando essa ideia, Sara considera que o atual ambiente de crise e a disputa desigual que acontece também no interior da escola são fatores centrais a ter em conta nesta discussão. Na sua opinião, " a sociedade está doente. As crianças estão a levar por tabela”, e sublinha que “enquanto nós não reformularmos o sistema de 
ensino nas escolas, não educamos pais, nem educamos filhos".

\section{Discussão}

Ainda que preliminares, considera-se que os resultados aqui apresentados permitem tecer algumas considerações.

Inicialmente, considera-se pertinente reconhecer que porventura alguns dos distúrbios referidos poderão não o ser, se entendidos num quadro de referência distinto daquele que é usado numa abordagem tendencialmente biomédica. Ou seja, assim como Sara entende que as crianças estão vivenciando os resultados de uma "sociedade [que] está doente", Jaccard 24 admite, em referência ao campo da psiquiatria, que não há loucos, as sociedades é que o são, pelas formas opressivas que tendem a perpetuar. Desse ponto de vista, a doença ou o distúrbio é, então, explicado como "desvio à norma que a sociedade, manifestando incapacidade em integrar os indivíduos, cataloga" 25 (p. 42). Por conseguinte, e apesar de integrarem formalmente o campo da saúde mental, muitos desses distúrbios dizem respeito a disciplinas que não estão diretamente ligadas ao universo da medicina, tal como tradicionalmente o conhecemos. Pelo contrário, é sabido que as trajetórias do sofrimento e da dor nem sempre são explicadas e resolvidas pelos desígnios médicos.

Percebe-se, também nesta linha, que a classificação tem efeitos particulares quando se refere a comportamentos de pessoas. Mais do que isso, estar consciente desse exercício de classificação tende a propiciar modificações comportamentais. Ou seja, "a partir de um diagnóstico bem estabelecido, qualquer comportamento inesperado da criança passa a ser justificado pela doença que ela apresenta" ou pelo rótulo que lhe é nomeado 26 (p. 901). Essa atitude de localizar o problema na criança leva, por conseguinte, à estigmatização da própria criança, até então considerada sadia, pela incorporação desse rótulo 27. Apesar de os problemas de escolarização se basearem especificamente nas características individuais e ser-lhes tendencialmente associado um cunho patológico, alguns autores defendem que é possível contrariar este movimento 6,10,28,29. Sugerem, para tal, que esses distúrbios sejam analisados com base nas condições sociais e econômicas de uma determinada época e contexto histórico, tendo em consideração a qualidade das mediações estabelecidas em diferentes ambientes, tais como a escola e a família 29. Adicionalmente, propõem que essa discussão seja focada naquilo que a sociedade atual vem ou não fazendo para favorecer as experiências escolares e de vida das crianças, dos jovens e das suas famílias 3,9.

Paralelamente, importa esclarecer que, independentemente de se adotar uma perspectiva biomédica para discutir o fenômeno da medicalização, reconhecemos que o medicamento resulta de importantes avanços da medicina, cujo contributo é incontornável para a melhoria da qualidade de vida das pessoas ${ }^{25}$. Nesse sentido, e ainda que em alguns casos (por exemplo, psicotrópicos) não se conheçam totalmente os seus efeitos, é inquestionável a eficácia dos medicamentos em alguns níveis específicos já estudados 23. Em relação a essa premissa, interroga-se então o (potencial) contributo da estratégia pedagógica na promoção do sucesso das crianças e dos jovens em idade escolar. E assim sendo, que lugar se reserva para a diferenciação de metodologias de trabalho para a criação de lógicas de participação ativa dos alunos e, essencialmente, para o aumento do interesse das crianças e dos jovens na escola e na sala de aula? Mais, reconhecendo que "aparatos técnicos de diagnóstico, como o microscópio, aparelhos de raio $X$, fármacos, de um modo geral, desempenham um papel fundamental na definição daquilo que é normal ou patológico" 30 (p. 138), que espaço sobra à escola para questionar também ela as suas tecnologias educativas, relacionais e comunicacionais perante a emergência apressada desses rótulos que tendem a surgir?

Do mesmo modo, este estudo sugere que, em diversas situações, os profissionais de educação estão convictos de que o uso do medicamento é responsável pela variação dos comportamentos da criança, excluindo outras variáveis, como as experiências no interior da sala de aula, designadamente no nível das práticas docentes e do ambiente na escola 26,30. Indubitavelmente, a valorização profissional em termos de remuneração, as condições de trabalho, o projeto pedagógico de cada escola, a autonomia administrativa das escolas, o tempo de permanência das crianças e dos jovens em aula, o número de alunos em sala 9 , entre tantas outros, são aspectos fundamentais que devem ser levados em conta a esse respeito. Percebe-se que esse fenômeno de medicalização do discurso escolar em nada parece contribuir para a defesa dos direitos da criança 31 . Pelo contrário, "a classificação das doenças adotadas por uma sociedade reflete sua estrutura institucional e a origem social das doenças está na necessidade da isenção de culpa das instituições” 27 (p. 1183) Assim, esse fenômeno de medicalizar desresponsabiliza a escola, reforçando potenciais fragilidades das crianças e das suas famílias. Mais, realça inúmeras vezes a dimensão segregadora 
veiculada por instituições de enorme relevância, como é o caso da escola.

É, de fato, cada vez mais frequente, na escola, deslocar-se o eixo da discussão político-pedagógica para causas e soluções médicas, inacessíveis à educação ${ }^{32}$. Afinal, se " a escola encaminha, aceita o diagnóstico e até modifica suas atitudes em função dele, ela pode ser considerada uma instituição de legitimação desse diagnósti$c o " 27$ (p. 1179). Ao invés de promover o sucesso educativo e o desenvolvimento integral dos alunos sinalizados ou com indicação médica para usar a medicação a partir de diagnósticos nebulosos, o papel da escola passa, então, por um registo caritativo que reafirma a inferioridade em que se encontram estes alunos em relação aos colegas 33. A esse propósito, vários autores sugerem o questionamento urgente das medidas que estão sendo propostas para atuação dentro do espaço escolar e reclamam estratégias complementares, nomeadamente de natureza psicoterapêutica 28,31,34,35. Isso baseia-se na ideia de que "as crianças devem ser entendidas ou não, a partir do que o meio sociocultural lhes disponibiliza não só concretamente, em termos de oferta dos instrumentos materiais necessários para a aprendizagem, mas também dos processos de raciocínio" adquiridos ao longo de milhares de anos de evolução 29 (p. 533).
Finalmente, reconhecemos que esta problemática não se restringe apenas ao espaço da escola e aos seus atores 3,23. Pelo contrário, atravessa outras instituições de significativa importância na vida das crianças e dos jovens, as quais são em boa medida responsáveis pela sua integração e sucesso, não apenas ao nível educativo, mas também ao nível pessoal e social. Fica, por conseguinte, claro que a tarefa de implementar, aplicar e fazer cumprir os direitos das crianças, ratificados pela Convenção da Organização das Nações Unidas (ONU) e transpostos para a legislação interna dos diferentes países, não cabe apenas ao Estado e às suas instituições, mas a toda sociedade civil 36 . Assim, recuperando o discurso de Ana - que admite que o filho não gosta de tomar a medicação e se compara a "um velhinho que só toma comprimidos" - constata-se a falta de envolvimento das próprias crianças e jovens em decisões sobre a sua saúde e a sua vida, isto é, parece que nem sempre são reconhecidos como cidadãos com direitos para além de necessidades 37 . O(s) espaço(s) em que se movem nem sempre são permeáveis à sua plena participação. Trata-se, por isso, de uma questão de cidadania na qual instituições públicas e políticas deveriam estar francamente envolvidas, partilhando responsabilidades e construindo percursos realmente securizantes 38,39 . 


\section{Colaboradores}

S. C. Pais realizou a pesquisa que deu origem ao artigo, interpretou e analisou os dados e redigiu o texto. I. Menezes e J. A. Nunes colaboraram na concepção, revisão crítica e edição final do artigo.

\section{Agradecimentos}

Os autores agradecem a todos os participantes do estudo e ao financiamento de um projeto de pós-doutoramento pela Fundação para a Ciência e a Tecnologia.

\section{Referências}

1. Mills C. Psychotropic childhoods: global mental health and pharmaceutical children. Children \& Society 2014; 28:194-204.

2. Maturo A. Medicalization: current concept and future directions in a bionic society. Mens Sana Monogr 2012; 10:122-33.

3. Arora T, Mackey L. Talking and listening to children diagnosed with ADHD and taking psychostimulants. In: Billington T, Pomerantz M, editors. Children at the margins: supporting children, supporting schools. Staffordshire: Trentham Books; 2004. p. 109-25.

4. Breggin PR. Brain-disabling treatment: drugs, electroshock, and the psychopharmaceutical complex. New York: Springer; 2008.
5. Durkheim E. Critical Assessments of leading sociologists. London/New York: Routlegde; 2001.

6. Moysés MA, Collares CA. Medicalização do comportamento e da aprendizagem: a nova face do obscurantismo. In: Viégas LS, Ribeiro MI, Oliveira EC, Teles LA, organizadores. Medicalização da educação e da sociedade. Ciência ou mito? Salvador: Edufba; 2014. p. 21-46.

7. Lord J, Paisley S. The clinical effectiveness and cost-effectiveness of methylphenidate for hyperactivity in childhood, version 2. London: National Institute for Clinical Excellence; 2000.

8. Petrina S. The medicalization of education: a historiographic synthesis. Hist Educ Q 2006; 46: 503-31. 
9. Collares CA, Moysés MAA. Educação na era dos transtornos. In: Viégas LS, Ribeiro MI, Oliveira EC, Teles LA, organizadores. Medicalização da educação e da sociedade. Ciência ou mito? Salvador: Edufba; 2014. p. 47-69.

10. Barbosa RL. Pele de cordeiro? Associativismo e mercado na produção de cuidado para as doenças raras. Lisboa: Chiado Editora; 2015.

11. Herpin N. A sociologia americana: escolas, problemáticas e práticas. Porto: Edições Afrontamento; 1982.

12. Bosk E. Between badness and sickness: Reconsidering medicalization for high risk children and youth. Child Youth Serv Rev 2013; 35:1212-8.

13. Nettleton S. The sociology of health and illness. Oxford: Polity Press; 1995.

14. Fontana A, Frey JH. Interviewing: the art of science. In: Denzin NK, Lincoln YS, editors. Handbook of qualitative research. Thousand Oaks: Sage Publications; 1994. p. 361-76.

15. Luders C. Field observation and ethnography. In: Flick U, Kardoff E, Steinke I, editors. A companion of qualitative research. Thousand Oaks: Sage Publications; 2004. p. 222-30.

16. Singh I. A framework for understanding trends in ADHD diagnoses and stimulant drug treatment: school and schooling as a case study. BioSocieties 2006; 1:439-52.

17. Ludermir AB. Desigualdades de classe e gênero e saúde mental nas cidades. Physis (Rio J.) 2008; 18:451-67.

18. Burke M. Resisting pathology: GID and the contested terrain of diagnosis in the transgender rights movement. In: McGann PJ, Hutson D, editors. Sociology of diagnosis. v. 12. Bingley: Emerald Group Publishing; 2011. p. 183-210.

19. Graham L. Out of sight, out of mind/out of mind, out of site: schooling and attention deficit hyperactivity disorder. Int J Qual Stud Educ 2007; 20:585-602.

20. Conrad P. The medicalisation of society. Baltimore: Johns Hopkins University Press; 2007.

21. Coppock V. Medicalising children's behaviour. In: Franklin B, editor. The new handbook of children's rights: comparative policy and practice. London/ New York: Routledge; 2002. p. 139-59.

22. Vallée M. Resisting American psychiatric: French opposition to DSM-III, biological reductionism, and the pharmaceutical ethos. In: McGann PJ, Hutson D, editors. Sociology of diagnosis. v. 12. Bingley: Emerald Group Publishing; 2011. p. 85-110.

23. Brozozwski F, Caponi S. Medicamentos estimulantes: uso e explicações em casos de crianças desatentas e hiperativas. Cadernos Brasileiros de Saúde Mental 2015; 7:1-23.
24. Jaccard R. A loucura. São Paulo: Jorge Zahar Editor; 1979.

25. Alves F. A doença mental nem sempre é doença. Racionalidades leigas sobre saúde e doença mental - um estudo no Norte de Portugal. Porto: Edições Afrontamento; 2011.

26. Brzozowski FS, Brzozowski JA, Caponi S. Classificações interativas: o caso do transtorno de déficit de atenção com hiperatividade infantil. Interface Comun Saúde Educ 2010; 14:891-904.

27. Brzozowski FS, Caponi S. Transtorno de déficit de atenção com hiperatividade: classificação e classificados. Physis (Rio J.) 2009; 19:1165-87.

28. Moysés MAA. A institucionalização invisível: crianças que não-aprendem- na- escola. Campinas: Mercado das Letras; 2001.

29. Tuleski S, Eidt N. Repensando os distúrbios de aprendizagem a partir da psicologia histórico-cultural. Psicolo Estud 2007; 12:531-40.

30. Mendes F, Ferreira J. Novas tecnologias e saúde: implicações políticas e sociais. In: Alves F, organizador. Saúde, medicina e sociedade: uma visão sociológica. Lisboa: Pactor; 2013. p. 137-60.

31. Collares C, Moysés M. Preconceitos no cotidiano escolar: ensino e medicalização. São Paulo: Cortez Editora; 1996.

32. Legnani V, Almeida S. A construção da infância: entre os saberes científicos e as práticas sociais. Estilos da Clínica 2004; IX:102-21.

33. Uribe C, Rojas R. Factores culturales en el trastorno por déficit de atención e hiperactividad: habla la mamá. Rev Colomb Psiquiatr 2007; 36:255-91.

34. Macleod G. Identifying obstacles to a multidisciplinary understanding of 'disruptive' behavior. Emot Behav Diffic 2010; 15:95-109.

35. Harwood V, Allan V. Psychopathology at school: theorizing mental disorders in education. Abingdon: Routledge; 2014.

36. Cordeiro M. Crianças e famílias num Portugal de mudança. Lisboa: Fundação Francisco Manuel dos Santos; 2015.

37. Pais SC, Guedes M, Menezes I. The values of empowerment and citizenship and the experience of children and adolescents with chronic disease. Citizenship, Social and Economics Education 2012; 11:133-44.

38. Lister R. Inclusive citizenship: realizing the potential. Citizensh Stud 2007; 11:49-61.

39. Guarido R. A medicalização do sofrimento psíquico: considerações sobre o discurso psiquiátrico e seus efeitos na educação. Educação e Pesquisa 2007; 33:151-61. 


\section{Abstract}

Children and youth reach school with different starting points. It is not known for sure how far these children and youth will go, and what path the school holds for them, particularly at a stage in which teachers are divided in multi-tasking (with some tasks that are merely administrative). Meanwhile, it is increasingly common to explain students' "inappropriate" behavior in biomedical terms. The increasing emergence of disorders and deficits calls for critical reflection on what they actually involve in public health terms. This article addresses the school's role in the educational achievement and comprehensive development of students flagged for or with clinical indication of medication based on "fuzzy" diagnoses. The concept of medicalization acquires a central position, and the article discusses its implications based on a set of field notes and interviews with parents and teachers in the North of Portugal.

Medicalization; Schools; Child; Adolescent

\section{Resumen}

Es sabido que a la escuela llegan niños y jóvenes con diferentes puntos de partida. Lo que no se sabe con seguridad es hasta dónde llegan esos niños y jóvenes, $y$ qué trayectoria les depara la escuela, particularmente, en el estadio en el que los profesionales de educación se ven divididos entre innumerables tareas (algunas meramente administrativas), $y$ donde parece que es cada vez más común atribuirle al comportamiento "poco adecuado" de los alumnos explicaciones de naturaleza tendencialmente biomédica. Frente a la emergencia creciente de trastornos y déficits es, de este modo, inevitable reflexionar críticamente a cerca de lo que efectivamente suponen en términos de salud pública. Este artículo se centra en una investigación sobre el papel de la escuela en el éxito educativo, y en el desarrollo in tegral de los alumnos señalados o con indicación médica para la ingestión de medicación a partir de diagnósticos "nebulosos". El concepto de medicalización adquiere una dimensión central y sus implicaciones se discuten basándose en un conjunto de notas de campo y entrevistas realizadas con padres y profesionales de educación de la Zona Norte de Portugal.

Medicalización; Instituciones Académicas; Niño; Adolescente
Recebido em 08/Out/2015

Versão fina reapresentada em 14/Jan/2016 Aprovado em 24/Fev/2016 